\title{
AVRUPA TOPLULUKLARI ADALET DIVANI VE TEMEL HAKLAR
}

\author{
Prof. Dr. Füsun ARSAVA*
}

ATAD'ın temel haklann teminatı alanında ozel bir sorumluluk taşımasında iki temel faktör rol oynamaktadır. Birincisi, Topluluk Hukuk düzeninde bir anayasa yahut kanun hiyerarşisinde bir temel hak katalogunun bulunmaması, diğeri temel haklann korunmasına, Topluluğun dayană̆ı olarak bir devletin Topluluğa katılmasının vazgeçilmez ơn koşulu olarak, ðzel bir önem verilmesidir.

AB bugüne kadar gerçekten bağlayıcı bir hukuki tasarnufla saptanmı̧̧ bir temel hak kataloğuna sahip deł̧ildir. Ne Avrupa Parlamentosunun 12.04.1989 (ABL.C 120, 16.05.1989, 51) tarihli Temel hak ve ozgürlüklere ilişkin bildirisi ne de işçilerin temel sosyal haklanna ilişkin 11 üye devletin devlet ve hükümet başkanlannca 8 ve 9.12.1989 da kararlaştırılan Topluluk Şartı (Kommision der EG, Amt für amtliche Veroffentlichungen, Luxemburg, 1990) şeklen bőyle bir hukuki etkiye sahip değildir.

Temel hakların korunmasının önemi mamafih tekrar tekrar kabul edilmektedir. Topluluk anayasa düzeni olarak geçerli olan kurucu anlaşmaların orjinal metninde zımmen kabul edilen bu durum Avrupa Tek Senedinde açık olarak ifade edilmiştir. Avrupa Tek Senedinin Praămbel'ında üye devletler ortak olarak demokrasiye arka çıkma kararlılıklarını ifade etmişler, bu meyanda üye devletlerin anayasalanında, kanunlarında, Avrupa Insan Hak ve Özgürlükleri Konvansiyonunda ve Avrupa Sosyal Sartunda tanınan temel haklara, ozcllikle özgürlük, eşitlik ve sosyal adaleti destekleyeceklerini ifade etmişlerdir.

01.11.1993'te yürürlüğe giren Avrupa Birliği'ne ilişkin Maastricht anlaşması temel haklara ilişkin olarak bir çok hüküm içermektedir. Bu çerçevede ơzel ơnem taşıyan hüküm madde F/2'dir. Madde hükmü, Birliğin 04.11.1950'de Roma'da imzalanan Avrupa Insan Hak ve Özürlükleri Konvansiyonunda yer alan ve üye devletlerin ortak anayasa geleneklerinden doğan, temel haklara saygı göstereceł̆i ifade edilmektedir.

* A.U. Siyasal Bilgiler Fakültesi Oğretim Oyesi. 
Ortak Dış Politika ve güvenlik politikayla ilgili V. Başlık, Md. J. 1 fıkra 2 "... demokrasi ve hukuk devleti ve insan haklarına ve temel ozgürlüklere saygının geliştirilip pekiştirilmesi;"

Adalet ve Içişlerinde işbirliği ile ilgili VI. Başlık, Md. K. 2 "... 4 Kasım 1950 tarihli Insan haklarına ve Temel Ơzgürlükleri koruma Avrupa Sözleşmesi ile.... saygı içinde ..." ayn şekilde temel haklarla ilgili düzenlemeler içermektedir.

Temel hakların korunması bakımından oneme sahip diger bir döküman, Avrupa Parlamentosu, Konsey ve Komisyon'unun 5.4.1977 (AB. C. 103, 27.4.1997, 1) tarihli ortak bildirisi ve Avrupa Konseyi'nin Nisan 1978 tarihli Kopenhag'ta karara bağlandığı demokrasi bildirisidir (Bulletin der EG, 1978, Nr. 3, S. 5). Bu bildiride devlet ve hükümet başkanları açıkça temel hakların korunmasının Avrupa Topluluklarına katılmanın ön koşulu olduğunu vurgulamışlardır. Bildiride parlamenter demokrasi ve insan haklarına saygı ve bunların korunması Avrupa Toplulugu'na katılmanın temel elementi olduğu ifade edilmiştir.

Divan, Topluluk Hukuk düzeni bakımından temel hakların geçerliliğini içtihatlarında tanımadan önce, negatif bir davranış sergilemiş ve ulusal anayasalar tarafından korunan temel haklara istinat eden açıklamalara karşı, Topluluk tasarruflarının geçerliliğinin münhasıran Topluluk Hukukan göre tayin edilebileceğini ve ulusal hukuka istinat edilemeyeceğini ifade etmiştir (4.2.1959 tarihli karar, Stork/Hohe Behörde, Rs. 1/58, Slg. S. 43; 15.7.1960 tarihli karar, Präsident Ruhrkohler - Verkaufsgesellschaft u.a/Hohe Behörde, verb. Rs. 36-38/59 und 40/59, Slg. S. 885).

Temel hakların Topluluk Hukuk düzeninin ayrılmaz bir parçası olarak ilk kez Stauder (12.11.1969 tarihli karar, Rs. 29/69, Slg. S. 419) davasında zikredildiğini görüyoruz. Bu kararda Divan bir Alman mahkemesi tarafundan arzedilen, Komisyon'un bir kararının ilgili bőlümünün, Toplụluk Hukukunun genel ilkeleriyle bağdaşıp bağdaşmadığı sorusunu hükmü yorumlayarak cevaplandırmıştır. Divan tartışmalı normun yorumundan, temin etmekle mütellef olduğu Topluluk genel hukuk ilkeleri içinde yer alan temel hakları ihlal eden bir sonuç çıkarılamayacağını ifade etmiştir.

Divan daha sonra bu içtihatını üye devletlerin ortak anayasa hukuku geleneklerine (17.12.1970 tarihli karar, Internationale Handelsgesellschaft, Rs. 11/70, Slg. S. 1125) ve üye devletlerin taraf olduğu uluslararası anlaşmalara atuf yaparak güçlendirmiştir. Üye devletlerin işbirliği yaptığı uluslararası anlaşmalara ilişkin atıf ilk kez 14.5.1974 (Rs. 4/73, Slg. J. 491) tarihli Nold kararında sőz konusu olmuştur.

Bu kararda Divan Topluluk Hukuk düzeninde temel hakların statüsüne ilişkin görüşünü büyük ölçüde yansıtmıştır. Buna göre genel hukuk prensiplerine dahil olan temel hakları Divan temin etmekle mükelleftir. Bu haklann tamininde Divan üye devletleri ortak anayasa geleneklerinden hareket edecektir.

Divan üye devletlerin anayasaları tarafından tanınan ve korunan temel haklarla bağdaşmayan hiçbir önlemi hukuki olarak kabul etmeyecektir. Aynı şekilde, üye devletlerin akdine katıldıkları yahut daha sonra katıldıkları insan haklarına ilişkin uluslararası anlaşmalar da Topluluk Hukuku çerçevesinde dikkate alınacaktur. 
Divanın içtihatlanyla Topluluk Hukuk düzenine temel haklanın dahil edilmesi, üye devletler hukuk düzenlerinde ortak olan genel hukuk prensiplerine istinat ettirilmektedir. Genel hukuk prensiplerine AT anlaşması 215. maddesinde akid dışı sorumluluk alanında da atuf yapmaktadır.

Genel hukuk ilkeleri içtihatlarda Topluluk Hukuk kaynağı olarak kabul edilmekte ve Topluluk Hukuk düzenindeki boşluklarin doldurulmasında ozel olarak uygun mütalaa edilmektedir.

Ihdası bakımından muayyen bir yơntem bulunmayan, ilk sırađa maddi anlamda normatif bir kategori oluşturan genel hukuk ilkeleri, üye devletlerin ulusal hukuk düzenlerinden ve uluslararası hukuk düzeninden istihraç edilmektedir.

Bu prensiplerden bazılan yazılı Topluluk hukukuna özel bir damga vurmaktadır. Divan içtihatlarında uluslararası hukuka ilişkin olarak, Avrupa Insan Hakları ve Temel Özgürlükleri Konvansiyonunun yanısıra, diğer uluslararası anlaşmalar da dikkate alınmaktadır. Defrenne karannda (15.6.1978 tarihli karar, Rs. 149/77, Slg. 1365) Avrupa Sosyal Şaruna, Uluslararası Çalışma Örgütü'nün 111 no'lu anlaşmasına, Orkem ve Solvay kararlarinda (18.10.1989 tarihli karar Orkem / Kommisssion, Rs. 374/87, Slg. S. 3283 , ve Solvay/Kommission, Rs. 27/88, Slg. S. 3355) BM Medeni ve siyasi haklar sozzleşmesine atıf yapılmıştr. Divan içuhatlarında bu enstrumanlar Uluslararası Hukukun bağlayıcı kurallan olarak değil, üye devletler hukuk düzenlerine ortak genel hukuk ilkelerinin saptanması bakımından kullanılmıştır. Aynı durum ulusal Hukuk bakımından da geçerlidir. Divan ortak anayasa gelencklerine ozel bir yer vermiştir. Örneğin Nold davasında üye devletlerin anayasalarında tanınan ve korunan temel haklarla bağdaşmayan onlemlerin hukukî kabul edemeyeceğini vurgulamıştır. Aynı zamanda Divan kimi vesilelerle -Örneğin Hauer davasında- Topluluk Hukuk düzeninin bir tasarrufuyla temel hakların ihlal edilip edilmediği sorusunun sadece Topluluk Hukuk düzeni ışığında değerlendirilebileceğini, zira muayyen bir üye devletin anayasa veya yasama düzenine bağlı değerlendirmelerin Topluluk Hukuk düzeninin birlik ve etkinliğini bozacağını, bu nedenle kaçınılmaz olarak ortak pazann birliğini bozacağını ve Topluluğun birlikteliğini tehlikeye sokma sonucu doğacağını ifade etmiştir.

Topluluk hukukunun Avrupa Insan Hak ve Temel Öggürlükleri Konvansiyonu ile ilişkisinin değerlendirilmesinde, tüm üye devletlerin bu konvansiyonun tarafı olmasının büyük önemi vardır. Divan, AtHS'ne auf yaptı̆̆ ilk karannnda bu hususa işaret etmiştir (28.10.1975 tarihli karar, Rutili, Rs. 36/75, Slg. S. 1219, Rdnr. 32). Bu karar konvansiyonun Fransa tarafindan onaylanmasından hemen sonra alınmışur.

Üye devletlerin taraf olduğu ortak bir anlaşma olarak, Topluluğun da konvansiyon ile üye devletler gibi bağlı olduğunun iddia edilmesi fonksiyonel ve sınırlı halefiyet sorunlarını gündeme getirmektedir.

Üye devletler tarafindan Topluluğa verilen fonksiyon ve yeckiler bu görüşe göre, üye devletler bakımından konvansiyondan doğan hukuki sinırlamalara tabidir.

GATT'ın Topluluk bakımından bağlayıcı etkisinin tanınmasında benzer görüşe istinat eden Divan (12.12.1972 tarihli karar, Intemational Fruit Company, verb. Rs. 21$24 / 72$, Slg. 1219), ancak hiçbir zaman Avrupa Insan Hak ve Temel Ozgürlükleri Konvansiyonunun Topluluğu bu niteliği ile bağladığını saptamamışır. Divan Insan 
Haklan Konvansiyonunu daha çok Insan haklan ile ilgili diğer Uluslararası anlaşmalar yanısıra temel hakların Topluluk seviyesinde teminatina esas olan genel hukuk prensiplerinin saptanmasında vurgulanmışur.

Pescatores'in radikal Uluslararası Hukuk ve Insan Haklan yanlısı olan bu tezi tam olarak ikna edici deģildir. Bu tez Avrupa Insan Hakları Komisyonu'nun tutumuna da ters düşmektedir. Avrupa Insan Haklanı Komisyonu çeşitli, direkt yahut endirekt Avrupa Topluluklarına yönelik şikayetler çerçevesinde kendisini ratione personae yetkisiz ilan etmiştir (Avrupa Insan Haklan Komisyonu kararlan, 10.7.1978, CFDT/Europăische Gemeinschaften, Antrag Nr. 8030/77, DR 13, 231, 11.1.1989, C. Dufay/Europäische Gemeinschaften, Antrag Nr. 13539/88, 9.1.1990, CM \& Co/Bundsrepublik Deutschland, Antrag Nr. 13258/87, Pressemitteilung C (90) 19, 13.2.1990; T. Gregerich, Luxemburg, Karlsruhe, Strassburg - Dreistufiger Grundrechtsschutz in Europa?, Zeitschrift für ausländisches öffentliches Recht un Völkerrecht 50 (1990), 836).

Doğru olan husus anlaşma taraflarının uluslararası yahut uluslarüstü kuruluşlara, orneğin, Avrupa Topluluklarına yetkilerinin devri ile, Konvansiyondan doğan yükümlülüklerden kurtulamayacaklandır (Avrupa Insan Haklan Komisyonu CM \& Co Bundersrepublik Deutschland ile ilgili karannda bu gőrüşü ifade etmiştir). Aynı zamanda doğru olan diğer husus da, Konvensiyonun Topluluk Hukukundaki yeri ile ilgili olarak ortaya çıkan sonuçtur.

Topluluklan, üye devletlere halef olma anlamında, onlara eşit kılmak doğru gözükmemektedir. Toplulukların bu anlamda üye devletlere eşit kabul edilmesi, Topluluklara üye olmayan anlaşma taraflarının bu sonucu uygun bulmasın gerektirir.

Bu sonuç Divanın GATT ile ilgili yukarda işaret edilen karan ile teyit olmaktadır. Zira bu karar, GATT'in Topluluk bakımından bağlayıcı sonuçlar dogurmasını, üye devletlerin GATT alanıdaki yetkilerinin Topluluğa devrinin Avrupa Insan Hak ve Temel Özgürlükleri Konvansiyonuna taraf diğer anlaşma taraflarınca kabul edilmesine bağlamışur. (International Friut Company, Rs. 21-24/72 Slg. S. 1219, Rdnr. 16)

Avrupa Insan Hakları Konvansiyonuna atıf yapılan Divan içtihatlarının incelenmesinde, Divanın insan hakları konvansiyonu hükümlerini, hukuki anlamların teorik olarak açıklanmasından bağımsız olarak, Topluluk Hukukunun aynlmaz bir parçası olarak, genel Hukuk prensiplerinin ortaya çıkarılmasında bir araç olarak kullanıldığını görmekteyiz.

Avrupa Insan Hak ve Temel Ozgürlükleri Konvansiyonunun ilk kez açıķ̧a tartışma konusu edildiği Rutili davasında Divan (Rutili, 28.10.1975 tarihli karar, Rs. 36/75, Slg. 1219, Rdnr. 32) Yabancular polisiyle ilgili olarak Topluluk Hukukunda ongörülen yetki sınırlamalarını, 4.11.1950'de imzalanan Avrupa Insan Hak ve Temel Ozgürlükleri Konvansiyonunun $8,9,10$ ve 11. maddesinde ve bu konvansiyona ek 16.9.1963 tarihli 4 No'lu protokolün 2. maddesinde yer alan genel hukuk prensiplerinin bir yansıması olarak ifade etmiştir.

Kamu güvenliği ve düzeninin korunması için zikredilen maddelerde yer alan haklarda yapllacak sinurlamalar bu genel hukuk ilkesine göre demokratik bir toplumda bu haklann korunması için gerekli çerçeveyi aşamayacaktur. 
Johnson (15.5.1986 tarihli karar, Rs. 222/84, Johnson Slg. S. 1651) ve Heylens (15.10.1987 tarihli karar, Rs. 222/86, Heylens, Slg. S. 4112) kararlannda Divan, üye devletlerin ortak bir anayasa geleneği olarak ve Avrupa Insan Haklan ve Temel Ozgürlükleri Konvansiyonunun 6 ve 13. maddelerinde yer alan bir esas olarak haklann etkin olarak teminat altuna alınmasını, Topluluk hukukunun genel hukuk prensibi olarak ifade etmiştir. 18.5.1989 tarihli kararında Divan (Rs. 249/86, Kommission/Deutschland, Slg. S. 1263, Rdnr. 10) 1612/86 sayılı tuzưgün Avrupa Insan Hakları ve Temel Özgürlükleri Konvansiyonunun 8. maddesi ışığında yorumlanması gerektiğini, zira bu maddede yer alan aile hayatına saygı gösterilmesi hakkunın Topluluk Hukuku tarafindan tanınan bir temel hak olduğunu ifade etmiştir. Hoechst (21.9.1989 tarihli karar, Hoechst/Kommussion, Verb. Rs. 46/87, ve 227/88, Slg. S. 2859; 17.10 .1989 tarihli karar, Dow Benelux/Kommission, Rs. 85/87, Slg. S. 3137, Dow Chemical Iberica/Kommission, Verb. Rs. 97-99/87, Slg. S. 3165) ve Orkem (18.10.1989 tarihli Orkem/Kommission, Rs. 374/87, Slg. S. 3283) davalarında ATAD, Avrupa Insan Hakları ve Temel Özgürlükleri Konvansiyonunun spesifik organlar tarafindan, Avrupa Insan Hakları Divanı tarafından yorumunu, nitelikli bir yorum kaynağı olarak tanımıştur. Hoechst davasında Divan, konut dokunulmazlığı hakkının Topluluk Hukuk düzenine, üye devletlerde ortak bir hukuk prensibi olarak şirketler için deģil, gerçek kişiler için de tanındığını ifade etmiştir. Bu saptama diğerleri yanı sıra şu gerekçeye istinat ettirilmiş̧ir. Avrupa Insan Hakları ve Temel Özgürlükleri Konvensiyonunun 8. maddesinin koruma alanı kişiliğin serbest olarak geliştirilmesine matuftur; bu nedenle işletmelerin işyerleri maddenin teminat alanı kapsamına girmez.

Orkem kararında kendi aleyhinde beyanda bulunmama hakkı ile ilgili olarak bőle bir hakkın ne Avrupa Insan Hakları ve Temel Özgürlükleri Konvensiyonun 6. maddesinden ne de Avrupa Insan Haklan Divanı'nın içtihatlarından istihraç edilebildił̌ini ifade etmiştir. Bu arada Avrupa Insan Hakları Divanı Niemitz davasında (16.12.1992 tarihli karar, Rs. 72/1991/324/396) Avrupa Insan Hakları ve Temel Özgürlükleri Konvensiyonunun 8. maddesinin teminat alanının mesleki faaliyetleri ve iş alanlarını da kapsadığını yorumunda dile getirmiştir. Funke kararında (25.2.1993 tarihli karar, Rs. 82/991/34/407) kendi aleyhine tanıklk yapmama hakkı Konvensiyonun 6. maddesine istinat ettirilmiştir. Her iki Avrupa yargı organı içtihatları arasında az da olsa farklılıkların ortaya çıktğını inkar etmek mümkün gőrülmemektedir. ATAD Avrupa Insan Haklan Divanının içtihatlarıyla ilgili olarak, içtihatlarını Strasburg mahkemesine uyum anlamına revize ettiğini belirtmektedir. Kaçınılmaz olarak ortaya çıkan bu farklılıklar Avrupa Insan Hakları ve Temel Özgürlükleri Konvensiyonunun ATAD tarafından Topluluk hukukunun ayrılmaz bir parçası olarak görülmediği sonucunu veremez.

Topluluk Hukuk düzeni tarafından tanınan, özellikle Insan Haklan sözleşmesinde yer alan temel haklann teminat Topluluğun normatif ve idari faaliyetlerini aşmaktadır. Temel haklar üye devletlerin, Topluluk Hukuku içinde kalmak zorunda olan tasarrufları ile sağlanır. Divan, içtihatlarında bu çerçevede temel haklan, Topluluk Hukukunun denetimi dışında kalan bir konu olarak münhasıran ulusal hukuka ait bir alan olarak dile getirmiştir.

Bu sorunun üzerine gidildiği ilk dava Defrenne davasıdır. Defrenne davasında ilk olarak, cinsiyete dayalı ayrımcılığın ortadan kaldırılması, Topluluk Hukukunun ayrilmaz bir parçası olan temel haklara dahil kabul edilmiştir. Topluluğun Hukuki denetimi ulusal 
hukukun geçerli olduğu alanlan kapsayamaz. Bu denetim ulusal mahkemeler tarafindan ilgili ulusal hukuk esaslarına ve uluslararası hukuka göre gerçekleştirilir.

Cinéthéque kararında (11.7.1985, Rs. 60 ve 61/84, Slg. S. 2605) Divan genel bir formülasyon yapmışur. Divan temel hakların Topluluk hukuku seviyesinde riayetini temin edecektir. Ancak ulusal yasama organının alanına giren bir ulusal kanunun Avrupa Insan Hakları ve Temel Ozgürlükleri Konvensiyonu ile uyuşmadığını denetleyemez.

Iki sene sonra Demirel davasında (30.9.1987,Demirel, Rs. 12/86, Slg. 3719) benzer bir formülasyon ortaya çıkmışur. Divan Topluluk hukuk alanında temel haklara saygıyı temin edecektir. Ancak Topluluk hukuku çerçevesinde bulunmayan bir ulusal düzenlemenin Avrupa Insan Haklan ve Temel Ozgürlükleri Konvansiyonu ile bağdaşıp bağdaşmadığını denetleyemez.

Bu kararın ortaya koyduğu husus, temel hak alanında yapılan bir ulusal düzenlemenin Topluluk denetimin dışinda bırakılabilmesidir. Toplulukta ikamet eden Türk iş̧ileri bakımından ailelerin birleştirilmesi koşullanını saptayan bir Topluluk hukuk normu bulunmamaktadır. Tartışmalı ulusal düzenleme Topluluk normunun icrasına hizmet etmemektedir. Bu şekilde zımnen, e contrario, Topluluk Hukukunun icrasına hizmet eden ulusal düzenlemelerin, Topluluk hukuku tarafindan taninan temel hakların temini alanına girdiği kabul edilmiş olmaktadır. Bu sonuç Wachauf (13.7.1989 tarihli karar, Rs. 5/88, Slg. s. 2609) kararnnda da zımnen kabul edilmiştir. Buna göre Topluluk hukuk düzenlemelerinin icrasında temel hakların teminatı gereklerine üye devletler saygı gösterecektir.

Nihayet ERT kararında (18.6.1991 tarihli karar, Rs. C-260/89, Slg. S. 1-2925) şimdiye dek olan içtihata şu saptama ilave edilmiştir. Anlaşmalarla tanınan temel haklara istisna getiren ulusal düzenlemelerin Topluluk hukuk düzeninde tanınan temel haklarla uyum içinde olması gerekmektedir.

Temel haklar sürekli içtihatlara göre genel hukuk prensiplerine dahildir. Bunların korunması Divanın teminatı alundadır. Divan bu meyanda üye devletlerin ortak anayasa geleneklerinden ve üye devletlerin taraf olduğu yahut katıldığı insan haklarına ilişkin uluslararası anlaşmalardan hareket etmektedir (özellikle 14.5.1974 tarihli Nold davası. Rs. 4/73, Slg. 1974, 491, Rdnr. 13). Bu meyanda Avrupa Insan Haklanı Konvansiyonu ozel bir anlama sahiptir (özellikle 15.5.1986 tarihli 22/84, Johnson, Slg 1986, 1651, Rdnr. 18) ATAD'ı 13.7.1984 tarihli 5/88 Wachauf, Slg. 1989, 2609, Rdnr. 19) kararinda teyit ettiği üzere, tanınan ve temin edilen insan haklarına saygı ile bağdaşmayan önlemler Topluluk hukukuna uygun olarak kabul edilemez. Divan içtihatlanna göre, (bknz.: 11.7.1985 tarihli karar, 60/84, Cinéthéque, Slg. 1985, 2605, Rdnr. 26, ve 30.9.1987 tarihli karar, Rs. 12/86; Demirel, Slg, 1987, 3719, Rdnr. 28) Divan Topluluk hukuku çerçevesinde ihdas edilmemiş ulusal düzenlemeyi Avrupa Insan Haklan Konvansiyonu muvacehesinde değerlendiremez. Böyle bir düzenleme buna karşılık Topluluk hukuk düzeninin uygulama alanına girdiği takdirde, ATAD onkarar prosedürü çerçevesinde kendine başvurulduğu takdirde, arzeden mahkemeye bu düzenlemenin temel haklara uygunluğunu değerlendirmek bakımından gerekli yorum kriterlerini verir. Bu hakların korunmasını ATAD temin etmek durumundadır. Bu haklar ozellikle Avrupa Insan Hakları Konvansiyonundan doğmaktadır. 
Özellikle bir üye devlet hizmet edimi serbestisini engellemek için 56. madde ile bağlantuh olarak 66 . maddeye istinat ettiği takdirde, bu ulusal düzenlemenin genel hukuk ilkeleri ve temel haklar ışığında değerlendirilmesi gerekir. 66. maddede 56. madde ile bağlantulı olarak karşımıza çıkan istisnalar ilgili ulusal düzenleme için, ATAD tarafından temin edilen temel hakları uyum içinde olduğu takdirde geçerli kabul edilir.

Divanın Avrupa Insan Hakları Konvansiyonu ile bağlantılı ortaya çıkan bu içtihatları, Konvansiyonun uygulamada Topluluk hukukunun bir parçası olarak uygulandığını ortaya koymaktadır. Topluluk tasarruflan konvansiyon muvacehesinde yorumlanmaktadır. Yine konvansiyon bu tasarrufların geserliližinde esas alınmaktadır.

Topluluk hukuku alanında gerçekleştirildiği nispette üye devletlerin önlemleri de, ATAD tarafindan Avrupa Insan Haklan Konvansiyonu muvacehesinde denetlenebilir. Bu onlemler konvansiyonda tanınan temel haklarla uyuşmadikları nispette, Topluluk hukukuna aykırıdır; Topluluk hukukunun önceliği prensibinin sonuçları Avrupa Insan Haklan Konvansiyonu bakımından da, Topluluk hukukunun bir parçası olması nedeniyle doğar. Şimdiye dekki içtihatlarda açıklığa kavuşmayan sorun, konvansiyon hükümlerinin Topluluk hukuk alanında herhalükarda doğrudan sonuçlanını gősterip gőstermediği yahut Topluluk hukukunun bir kuralının uygulanması ile bağlantılı olarak strico sensu bu etkinin tanınıp tanınmadığıdır.

Sonuç olarak saptanması gereken husus, ATAD içtihatlarında temel hak kataloğuna şeklen aynı fonksiyonun tanındığıdır. Bu saptama konvansiyonda yer alan temel haklann Toplulukta geçerlilił̆i bakımından ATAD tarafından yapılan teorik açıklamaya ters düşmemektedir. ATAD tarafından bu geçerliliğin, Konvansiyonun Topluluk bakımından Uluslararası Hukuk anlamında bağlılığından çok, üye devletlerin ortak anayasa gelenekleri olarak açıklanması, konvansiyonda yer alan temel hakların Topluluk hukukunda hukukì sonuçlarının sınırlanması anlamını ıaşımaz.

Genel hukuk ilkelcrinin aslında kökleri üye devletlerin uluslararası hukuk yükümlülüklerine dayanır. Topluluğun konvansiyona taraf olmaksızın, konvansiyon hükümleri ile bağlı olması bir olgu olarak karşımızdadır. Ancak bunun Topluluk hukukunun üye devletlerin uluslararası hukuk baglanulan muvacehesinde yorumlanması ve uygulanması csasından hareketle açıklaması mümkündür (R. Bernhardt, Die Europăische Gemeinschaft als neuer Rechtstrăger im Geflecht der traditionellen zwischenstaatlichen Rechtsbeziehungen, Europarecht 1983, 199, auf s. 214).

Genel hukuk ilkelerinin saptanması için ózellikle üye devletlerin ortak anayasa geleneklcrine istinat edilmesi, temel hakların himaye seviyesinin konvansiyon standardına nazaran hiçbir şekilde düşürülmesi anlamını taşıyıp, yükseltilmesi anlamını taşır. Konvansiyon tarafından sunulan temel hak himayesi ATAD içtihatlarına göre Topluluk hukuk düzeni bakımından asgari bir temel standardı oluşturmaktadır.

Bütün bu içtihatların Avrupa Birliği'ne ilişkin anlaşmanın yürürlüğg girmesinden once oluşmuş olması, bu anlaşmada yer alan $\mathrm{F}$ maddesinin konvansiyonun Topluluk hukukundaki yeri bakımından hukuki sonuçlarııın araşurılmasını gerektirmektedir. Bu hüküm ilginç bir şekilde anlaşmanın L maddesi ile ATAD'ın yargı yetkisi dışında bırakılmıştır. Aynca bu durum Topluluk hukukunun tüm alanları bakımından yorum ve uygulama uyuşmazlıklarında yetkili olan ATAD'ın Avrupa Birligi bakımından temel haklann bağlayıcılığı konusunda fikir yürütememesi anlamını taşımaz. Madde L'nin 
madde F ile bağlantuli hukuki sonucu, Divanın temel haklara ilişkin yargı yetkisinin Avrupa Birliği'nin yetkili olmadığı alanlara genişletmesini engellemesidir.

Topluluk hukukunda şimdiye kadar sadece hukuk yaratılması ile gerçekleştirilen temel hak teminatu, primer hukukta madde $F$ ile bir dayanak elde etmiş̧ir. Konvansiyonda temin edilen temel haklara saygı, Avrupa Birliği anlaşmasının yürürlüğe girmesiyle bir Topluluk normu üzerinden anayasal anlamda bağlayıcılık kazanmışur. 